\title{
Asset Pricing in Created Markets
}

\author{
Richard G. Newell, Kerry L. PAPPS, AND James N. SANChirico
}

\begin{abstract}
We investigate the applicability of the present-value asset pricing model to fishing quota markets by applying instrumental variable panel data estimation techniques to 15 years of market transactions from New Zealand's individual transferable quota (ITQ) market. In addition to the influence of current fishing rents, we explore the effect of market interest rates, risk, and expected changes in future rents on quota asset prices. The results indicate that quota asset prices are positively related to declines in interest rates, lower levels of risk, expected increases in future fish prices, and expected cost reductions from rationalization under the quota system.
\end{abstract}

Key words: asset pricing, fishery management, tradable permits.

DOI: $10.1111 /$ j.1467-8276.2007.01018.x

Although recent experience with the sulfur dioxide trading program in the United States has changed many perceptions, there are still questions about how well tradable permit systems for environmental pollution, greenhouse gases, agricultural production, and natural resources can work in practice. Such skepticism is in part warranted by the limited number of ex post assessments on the performance of created markets. Because building the necessary institutions can require significant political and economic costs, it is imperative to develop an empirical record of the performance of created markets in practice.

One area where market-based systems are subject to a significant degree of skepticism is in the management of ocean fisheries. One such system is individual fishing quotas, in which the total catch is capped and shares of the catch are allocated. An individual transferable quota (ITQ) system results when transfer of the shares is permitted. Over time, the least efficient fishermen should find it more profitable to sell their quota rather than fish it, both reducing excess capacity and increasing the efficiency of vessels operating in the fishery.

Richard G. Newell is the Gendell Associate Professor of Energy and Environmental Economics at the Nicholas School of the Environment and Earth Sciences, Duke University, Durham, North Carolina and a University Fellow at Resources for the Future. James N. Sanchirico is a Senior Fellow at Resources for the Future, Washington DC 20036. Kerry L. Papps is a Ph.D. student in the Department of Economics at Cornell University, Ithaca, NY.

We are grateful to Suzi Kerr, the research assistants at Motu Economic and Public Policy Research (New Zealand) and Resources for the Future, and the New Zealand Ministry of Fisheries for the provision of confidential trading data. We also thank Resources for the Future and the New Zealand Ministry of Fisheries for providing funding for this research.
For ITQs to address the common pool problem in practice, it is important that quota markets are competitive and convey appropriate price signals. Price signals sent through the quota market are an essential source of information on the expected profitability of fishing and an important criterion for decisions to enter, exit, expand, or contract individual fishing activity. Quota prices also send signals to policymakers about the economic and biological health of a fishery. Arnason (1990) showed that under the assumption of competitive markets, monitoring the effect of changing the total allowable catch (TAC) on quota prices could be used to determine the optimal TAC.

In a previous study, Newell, Sanchirico, and Kerr (2005) (hereafter NSK) investigate the performance of ITQ markets using the most comprehensive dataset gathered to date for the largest system of its kind in the world. The panel dataset from New Zealand covers 15 years of transactions across the 33 species that were in the program as of 1998 and includes price and quantity data on transactions in more than 150 fishing quota markets. Markets exist in New Zealand both for selling the perpetual right to a share of a stock's TAC, as well as for leases of that right to catch a given tonnage in a particular year. NSK found that market activity appears sufficiently high to support a reasonably competitive market for most of the major quota species and that price dispersion has decreased over time. Investigating the asset and lease markets separately, they find evidence of economically rational behavior in each of the quota markets and their results show an increase in quota asset prices, consistent with increased profitability. 
We extend the analysis of NSK by econometrically examining the relationship between the annual lease and sale prices in the perpetual quota asset markets. A notable exception to the virtually nonexistent literature examining quota prices in fisheries is the paper by Batstone and Sharp (2003), which investigates the relationship between fishing quota sale and lease prices and changes in the total allowable catch for the New Zealand red snapper fishery (region 1). Batstone and Sharp (2003) find support for the relationship proposed by Arnason (1990). Other related research in fisheries includes Karpoff (1984a, 1984b, 1995) and Huppert, Ellis, and Noble (1996), who look at the relationship between license prices and fishery rents in Alaska salmon fisheries.

With competitive markets, rational asset pricing theory suggests that the price of an income-producing asset in period $t, p_{t}$, should be determined by the real per-period profits from the asset, $\pi_{t}$, and the real discount rate, $r_{t}$ :

$$
p_{t}=\sum_{j=0}^{\infty} \frac{E_{t}\left(\pi_{t+j}\right)}{\prod_{k=0}^{j}\left(1+E_{t}\left(r_{t+k}\right)\right)}
$$

where $E(\cdot)$ is the expectations operator. In our setting, equation (1) states that the current quota asset price should be equal to the present discounted value of all future expected earnings, where the lease prices represent the annual flow of profits from holding quota. The price of the quota asset, therefore, will vary across fish stocks and over time based on changes in expected future lease prices or changes in the expected discount rate over time.

Under the simplifying assumption that expected lease prices and discount rates remain constant in the future, the price of the asset would simply equal the lease price divided by the discount rate, or $p_{t}=\pi_{t} / r_{t}$. The expected rate of return from holding fishing quota (or dividend-price ratio) would be equal to $\pi_{t} / p_{t}$. Figure 1 supports the basic structure of such a relationship in New Zealand fishing quota, with the dividend-price ratio tracking both the level and the trend in New Zealand short-term interest rates over the sample period. For example, at the same time the dividend-price ratio fell by about half from $13 \%$ to $7 \%$, the interest rate as measured by New Zealand Treasury bills fell from $10 \%$ to about $4 \%$ in real terms. Overall, the quota dividend-price ratio is about $2 \%-3 \%$ higher than the risk-free

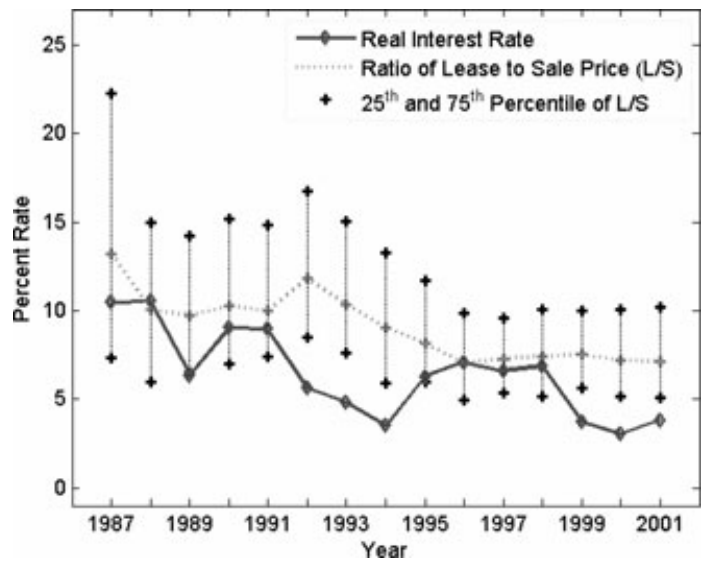

Note: Rates of return are medians (50th percentiles), 25th percentiles and 75th percentiles across fish stocks in each year. The real interest rate is based on New Zealand Treasury bills, deflated using the New Zealand consumer price index.

\section{Figure 1. Quota dividend-price ratio and market interest rates}

rate on average. Figure 2 likewise suggests a close, relatively linear association between asset and lease prices (in logs). The level of the average asset price is also approximately 10 times the lease price over the sample period, roughly equal to the present value of a perpetuity discounted at $10 \%$.

Figure 1 also shows that there is considerable cross-sectional variation in the dividendprice ratio across fish stocks markets, where the upper and lower plus signs represent the 25th and 75 th percentiles. Why might such variation exist? One reason could be that if fishers are risk averse they will prefer fish stocks with lower variance, other things equal. This effect is consistent with a higher discount rate, or higher required rate of return for riskier stocks. Such volatility could be associated with

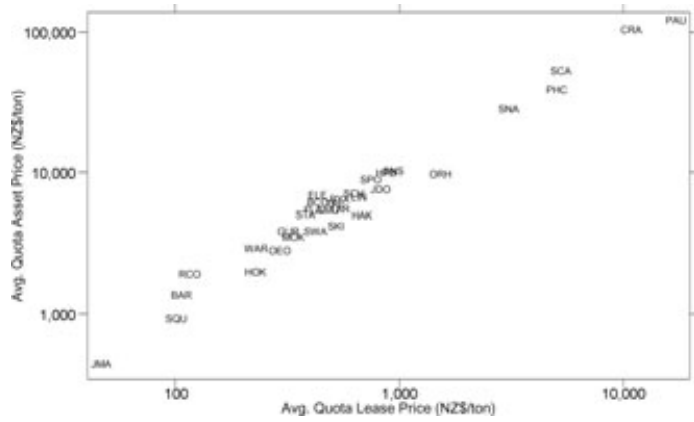

Note: Logarithmic scale. Averages by species. Year 2000 NZ\$. Data symbols are species abbreviations (see table 1).

Figure 2. Average quota asset price versus average quota lease price 
Table 1. Species Included in the New Zealand ITQ System as of 1998

\begin{tabular}{lcccc}
\hline Species & Abbreviation & Year Entered & Fish Stocks & Species Type \\
\hline Barracouta & BAR & 1986 & 4 & Offshore \\
Blue cod & BCO & 1986 & 7 & Inshore \\
Bluenose & BNS & 1986 & 5 & Inshore \\
Alfonsino & BYX & 1986 & 5 & Inshore \\
Rock lobster & CRA & 1990 & 9 & Shellfish \\
Elephant fish & ELE & 1986 & 5 & Inshore \\
Flatfish & FLA & 1986 & 4 & Inshore \\
Grey mullet & GMU & 1986 & 4 & Inshore \\
Red gurnard & GUR & 1986 & 5 & Inshore \\
Hake & HAK & 1986 & 3 & Offshore \\
Hoki & HOK & 1986 & 1 & Offshore \\
Hapuku and bass & HPB & 1986 & 7 & Inshore \\
John Dory & JDO & 1986 & 4 & Inshore \\
Jack mackerel & JMA & 1987 & 3 & Offshore \\
Ling & LIN & 1986 & 7 & Offshore \\
Blue moki & MOK & 1986 & 4 & Inshore \\
Oreo & OEO & 1986 & 4 & Offshore \\
Orange roughy & ORH & 1986 & 7 & Offshore \\
Oyster & OYS & 1996 & 2 & Shellfish \\
Paua (abalone) & PAU & 1987 & 10 & Shellfish \\
Packhorse rock lobster & PHC & 1990 & 1 & Shellfish \\
Red cod & RCO & 1986 & 4 & Inshore \\
Scallops & SCA & 1992 & 2 & Shellfish \\
School shark & SCH & 1986 & 7 & Inshore \\
Gemfish & SKI & 1986 & 4 & Offshore \\
Snapper & SNA & 1986 & 5 & Inshore \\
Rig & SPO & 1986 & 5 & Inshore \\
Squid & SQU & 1987 & 3 & Offshore \\
Stargazer & STA & 1986 & 7 & Inshore \\
Silver warehou & SWA & 1986 & 3 & Offshore \\
Tarakihi & TAR & 1986 & 7 & Inshore \\
Trevally & TRE & 1986 & 4 & Inshore \\
Blue warehou & WAR & 1986 & 5 & Offshore \\
\hline
\end{tabular}

natural variation in stock abundance and economic variability in costs and fish prices. Another explanation could be differences in the expected growth rate of profits over time (Melichar 1979), possibly due to differences in output price growth, changes in fish populations, or other factors affecting costs such as cost rationalization due to quota trading.

Using panel data econometric techniques on an updated NSK dataset, we estimate models that relate the asset price of quota to their annual lease (or rental) price and observed determinants of the growth rate and volatility of rents. Within this framework, we explore the relationship between asset and lease prices, as well as whether differences in asset prices are due to differential risks associated with holding quota across fish stocks and/or different expected growth rates in fishery rents in those stocks. These data are uniquely qualified to address these questions, because of the relatively long time series, breadth of markets, and cross- sectional heterogeneity, as the market characteristics are diverse across both economic and ecological dimensions (see table 1 for a list of species included). For example, in 2000 the export value of these species ranges from about NZ\$700 per ton for jack mackerel to about $\mathrm{NZ} \$ 40,000$ per ton for rock lobster. ${ }^{1}$

Consistent with asset pricing theory, we find a statistically (and economically) significant relationship between asset prices and contemporaneous lease prices. Stocks with a higher degree of biological volatility tend to have lower asset prices, and stocks that have rising returns or falling costs from fishing are found to have higher asset prices, ceteris paribus. Taken together, these results suggest that the price signals generated by the ITQ system are a good indication of the future profitability of

\footnotetext{
${ }^{1}$ Throughout this article, monetary values are the year $2000 \mathrm{New}$ Zealand dollars, which are typically worth about half a U.S. dollar. Tons are metric tons.
} 
individual fishing quota stocks. ${ }^{2}$ The magnitude of some interrelationships is muted relative to what the theory suggests, possibly due to measurement error.

Our analysis also contributes to the extensive literature investigating asset prices by utilizing micro-level trading data across multiple (related) markets to measure the relationships embedded in equation (1), and the relative importance of the different factors behind the heterogeneity in figure 1 . Nonfishery studies relevant to ours that investigate agricultural land prices and farming rents (e.g., Melichar 1979; Alston 1986; Falk 1991; Clark, Fulton, and Scott 1993; Just and Mirinowski 1993) or agricultural production quota (e.g., Barichello 1996; Wilson and Sumner 2004) typically focus on aggregate data and/or concentrate on a single market. For example, Falk (1991) models farmland prices in Iowa using aggregate price and rent data, and Wilson and Summer (2004) analyze the market for diary quota in California. The same holds for Batstone and Sharp (2003), who investigate a single quota market. Clark, Fulton, and Scott (1993) argue that a cross-sectional comparison of land markets can help illuminate the factors important in understanding the empirical relationship in equation (1).

In the next section, we provide a selected review of the literature modeling asset prices and dividends. This is followed by a description of the design of the ITQ system in New Zealand, paying particular attention to market characteristics. We then develop an empirical model that is appropriate to a multiple-asset setting like the New Zealand fishing quota market. We discuss the empirical specification, data sources, time-series properties of the data, estimation approach, and results, before we conclude by summarizing our findings.

\section{Modeling Asset Prices and Dividends}

The literature exploring the relationship between asset prices, dividends, and other rel-

\footnotetext{
${ }^{2} \mathrm{~A}$ referee raised the question of whether we should expect the behavior of fishermen to reflect linkages between capital and quota markets. Because fishermen often purchase equipment and vessels using commercially available capital, their decisions are linked with broader capital markets. Figure 1 and the econometric evidence presented herein also bring into question the oftenprevailing notion that fishermen do not behave in an economically sophisticated way, and lack an understanding of the relative cost of capital. Having said that, Karpoff (1985) investigates and finds evidence for the existence of nonpecuniary factors in the license prices of Alaska salmon fishery. An interesting question for further research is whether we might be able to undertake a similar analysis.
}

evant factors (e.g., firm size) is extensive. A thorough literature review is therefore beyond the scope of this article, and interested readers should consult Cochrane (2001) and Campbell, Lo, and MacKinley (1997) or the review articles by LeRoy (1989), Fama (1991, 1998), and Campbell (2000). ${ }^{3}$

Simplifying equation (1) under the assumption that the expected discount rate follows a martingale process yields ${ }^{4}$

$$
p_{t}=\sum_{s=0}^{\infty} \frac{E_{t}\left(\pi_{t+s}\right)}{\left(1+r_{t}\right)^{s+1}}
$$

Equation (2) illustrates how the asset price is dependent on the expected future stream of earnings, so that information available at time $t$ along with type of expectation process is important in modeling the relationship between asset prices and dividends. For example, if one assumes that expected future earnings are constant, then $E_{t}\left(\pi_{t+s}\right)=E_{t}(\pi)$. Huppert, Ellis, and Noble (1996) model and find support for an adaptive expectations process where $E_{t}(\pi)=\beta \pi_{t-1}+(1-\beta) E_{t-1}(\pi)$ with $\beta \in[0,1]$, and Karpoff (1984b) models a myopic process where $\beta=1$. Wilson and Sumner (2004) find support for a second-order adaptive expectation process in California dairy quota prices. Just and Miranowski (1993) test myopic, adaptive, and rational expectation regimes and find that farmland price data support myopic expectations. Falk (1991) finds a similar result. Orazem and Miranowski (1986) provide an empirical strategy for testing competing hypotheses of expectations regimes when direct measures of expectations are unavailable. Applied to farm acreage allocation decisions as a function of expected commodity prices, it yielded little evidence for favoring any of the three regimes.

If future profits (lease prices) grow at a constant rate $g$, then $\pi_{t}=(1+g) \pi_{t-1}+\varepsilon_{t}$, where $\varepsilon_{t}$ is a white noise error term. Taking expectations and solving equation (2) forward in time with $g<r$, the asset price follows

$$
p_{t}=\frac{\pi_{t}}{r_{t}-g} .
$$

\footnotetext{
${ }^{3}$ Recently, McGough, Plantinga, and Provencher (2004) investigate the implications of a rational expectations equilibrium in timber markets on the time series properties of timber prices.

${ }^{4}$ If the discount rates follow a martingale process, then the best predictor of future discount rates at time $t$ is the current rate, i.e., $E_{t}\left(r_{t+1}\right)=r_{t}$ (LeRoy 1989). This is supported empirically by econometric analyses of interest rates. For a more general analysis of time-varying rates, see Chapter 7 of Campbell, Lo, and MacKinley (1997)
} 
Equation (3) is the dynamic "Gordon growth model" (Campbell, Lo, and MacKinley 1997) that forms the basis of the majority of studies on the relationship between asset prices and dividends.

Due to a divergence between simple present-value relationships and empirical observations on agricultural land prices and rents during the 1970s and 1980s, a number of authors have extended this basic structure to include other factors, such as taxes (e.g., Robison, Lins, and VenKataraman 1985; Alston 1986), changes in risks (Barry 1980), and credit market constraints (Shalit and Schmitz 1982). Instead of investigating these many factors separately, Just and Miranowski (1993) develop a detailed structural model of the determinants of asset prices, which is a function of inflation, taxes, credit market imperfections, transaction costs, and risk aversion.

Others have focused on estimating a reduced form that is consistent with equation (2). For example, Burt (1986) argues that movements in asset prices may occur because of continued adjustment to past changes in returns, implying that the price does not adjust instantaneously to changes in expected future returns. In addition, expectations of future rents may be based on past, as well as current, values of $\pi_{t}$. He approximated the effect of both sources of dynamic behavior by using a multiplicative distributed lag specification for $\pi_{t}$, with a restriction that the lag coefficients sum to unity.

\section{Background on NZ ITQ System}

We include a brief review of the New Zealand ITQ system with special attention to the elements that are most relevant for our analysis. For further history and institutional detail, see Batstone and Sharp (1999), Yandle (2001), NSK, and the references cited therein.

The New Zealand government passed the Fisheries Amendment Act in 1986, creating a national ITQ system. The system initially covered seventeen inshore species and nine offshore species, which together expanded to a total of forty-five species by 2000 . Under the system, the New Zealand Exclusive Economic Zone (EEZ) is geographically delineated into quota management regions for each species based on the location of major fish populations. Rights for catching fish are defined in terms of fish stocks that correspond to a specific species taken from a particular quota management region. In 2000, the total number of fishingquota markets stood at 275 , ranging from 1 for the species hoki to 11 for abalone. As of the mid-1990s, the species managed under the ITQ system accounted for more than $85 \%$ of the total commercial catch taken from New Zealand's EEZ and from our calculations had an estimated market capitalization of about NZ\$3 billion.

The New Zealand Ministry of Fisheries sets a TAC for each fish stock based on an intertemporal biological assessment (including the prior year's catch level) and other relevant environmental, social, and economic factors. The TACs are legislated to maintain the fish population at a level (or move it to a level) that will support the largest possible annual catch (i.e., maximum sustainable yield), after an allowance for recreational and other noncommercial fishing. Not all species have their TACs adjusted for noncommercial uses, especially those in the offshore sector where there is little if any recreational fishing (see table 1). ${ }^{5}$ Most TACs remain constant from year to year and for many fish stocks (especially those of low value) there are no formal stock assessments (Annala 1996). When a TAC needs to be adjusted there is no automatic process, and the appropriate level of the adjustment is discussed with the quota owners (Sanchirico et al. 2006).

Individual quota were initially allocated to fishermen free of charge as fixed annual tonnages in perpetuity based on their average catch level over two of the years spanning 1982-1984. Beginning with the 1990 fishing year, however, the government switched from quota rights based on fixed tonnages to quota denominated as a share of the TAC. Compliance and enforcement is undertaken through a detailed set of reporting procedures that track the flow of fish from a vessel to a licensed fish receiver (on land) to export records, along with an at-sea surveillance program including onboard observers.

Given the uncertainty around the quantity and composition of catch, a fisherman's quota holdings represent a mix of ex ante and ex post leases, as well as asset purchases and sales to cover actual catch. Although there are

\footnotetext{
${ }^{5}$ For fish stocks with noncommercial interests, such as the red snapper fishery (Region 1), the TAC for the commercial fishery is denoted the total allowable commercial catch (TACC). For expositional reasons, we use TAC to refer to TACC for these fisheries.
} 
no official statistics, the general belief is that brokers handle a majority of the transactions between small and medium-sized quota (with a fee between $1 \%$ and $3 \%$ of the total value of the trade paid by the seller) and larger companies typically have quota managers on staff and engage in bilateral trades with other large companies. Whether ex ante or ex post transactions, fishing quota are generally tradable only within the same fish stock, and not across regions or species or years, although there have been some minor exceptions. ${ }^{6}$ The quota rights can be broken up and sold in smaller quantities and any amount may be leased or subleased any number of times. Virtually all leases are for one year or less. There are also legislative limits on aggregation for particular stocks and regions, and limitations on foreign quota holdings.

NSK find that the quota markets are active, with about 140,000 leases and 23,000 quota asset sales occurring between economically distinct private entities between 1986 and 2000an annual average of about 9,300 leases and 1,500 asset sales. Market participation has also increased over time with around $70 \%$ of quota owners taking part in a market transaction in 2000. Although some individual quota markets are thin, these tend to be of low economic importance in the size and value of the catch. The annual number of leases has risen ten-fold between 1986 and 2000, and the median percentage of total quota that are leased in these markets has risen consistently, from $9 \%$ in 1987 to $44 \%$ in 2000 . At the same time, the total number of quota asset sales declined from a high of about 3,200 sales in 1986 (when initial quota allocations for most species took place), leveling off to around 1,000 sales in the late 1990s. The median shows a similar decline, with the percentage of total outstanding quota sold per year being as high as $23 \%$ at the start of the program, gradually decreasing in subsequent years to around $5 \%$ in the late 1990 s. This pattern of asset sales is consistent with a period of rationalization and reallocation proximate to the initial allocation of quota, with sales activity decreasing after the less profitable producers have exited.

\footnotetext{
${ }^{6}$ During the time period of our analysis, in addition to the lease and asset markets, fishers had a number of ways to balance their quota holdings and catches within a 30 day window after landing their catch (see NSK). Sanchirico et al. (2006) describe these flexibility mechanisms, how they changed over time (mostly in October 2001), and their level of use.
}

\section{Empirical Analysis of Fishing Quota Asset Prices}

\section{Empirical Model}

Our empirical assessment of the relationship between quota asset prices and expected future profits from fishing quota is based directly on the dynamic Gordon growth model (equation (3)). Within this framework, we explore possible explanations for the heterogeneity in quota asset prices across the different fishing quota markets, as illustrated in figure 1. Potential reasons for the heterogeneity include different growth rates of profits due to expected changes in revenues or costs, or because fish stocks are associated with different risk premia.

It is straightforward to allow for different asset prices, profits, and expected growth rates of profits across fish stocks, $i$. To investigate different risk premia, we follow the methods employed in Alston (1986) and Cochrane (1992) by decomposing the discount rate into a real market interest rate, $\tilde{r}_{t}$, and an asset-specific risk premium, $\theta_{i}$. Formally, this leads to

$$
p_{i, t}=\frac{\pi_{i, t}}{\tilde{r}_{t}+\theta_{i}-g_{i}} \text {. }
$$

In fishing quota markets, a major difference in risks stems from ecological volatility, whereby some fish stocks have more variable populations from one year to the next. Because search costs depend on the stock size and location, greater fluctuations in population abundance could lead to greater harvest and cost uncertainty.

In our setting, another important issue arises when considering the application of equation (4), which, for simplicity, assumes continuous growth into the indefinite future. In particular, fishing quota markets are created to address the "tragedy of the commons," and our analysis includes a period over which there was a market-based transition away from regulated open access conditions. Typically, when quota markets are created, fishing capital and labor inputs are distorted and fish populations are depleted due to years of operating under regulated open access conditions. An implication of this is that there will likely be a divergence between the current lease-asset ratio and the longer-term equilibrium, at least early on in the market, because at that time the contemporaneous lease price is not a good indicator of future profitability. This means that the asset 
price of a stock anticipating rationalization would initially be relatively high compared to its lease price. This divergence would decline over time as the stock achieved its anticipated profit increases and higher lease prices. Figure 1 suggests support for this hypothesis, as the difference between the 25 th and 75 th percentiles follows a downward trend.

Why might the divergence decrease over time? Initially, trades of the perpetual right to fish will occur as high-cost fishers find it more profitable to sell their quota rather than fish it. The gains from trade and elimination of excess fishing capital should result in cost savings. In addition, in many fisheries the cost function is likely to be stock-dependent, so that costs increase as the fish stock size falls and it becomes harder to find the fish (i.e., searching costs increase). As a result, if the TACs are set to allow stock recovery, then the gains due to stock rebuilding will also be incorporated in the expectation of future costs. The ability to time fishing trips to higher product prices rather than being forced to operate in short seasons, along with the shift from maximizing quantity to maximizing quality, will also feature in near-term expectations of future revenue growth. ${ }^{7}$ These effects will likely dissipate over time as the potential gains are realized, where the rate of dissipation is an empirical question.

We modify equation (4) to account for these transitory effects by including a multiplicatively separable function, $\psi(\cdot)$, representing the transition associated with ITQs:

$$
p_{i, t}=\frac{\pi_{i, t}}{\tilde{r}_{t}+\theta_{i}-g_{i}} \Psi(\cdot) .
$$

We expect $\Psi(\cdot)$ to be greater than one, because asset prices in ITQ markets will initially be above the levels predicted by the long-run relationships due to short-run expected profitability gains. Furthermore, we expect it to be larger for stocks with greater short-term gains, but to be decreasing over time, as asset prices should converge to the long-run relationship after some interval of time, holding everything else equal. The arguments of $\Psi(\cdot)$ can include,

\footnotetext{
${ }^{7}$ The flexibility to time fishing trips when port prices are higher, and the elimination of large supply gluts of fresh product, have resulted in increases in price per pound of more than $40 \%$ in the Alaskan halibut ITQ fishery (Casey, Wilen, and Dewees 1995). The focus on quality is also evident in New Zealand, where fishermen have changed catching methods in the red snapper fishery in order to sell their catch on the highly profitable Japanese live fish market (Dewees 1998).
}

for example, time since the market was created, and variables that represent gains from trade and fish stock recovery.

\section{Empirical Specification and Data}

After adding and subtracting 1 in the denominator of equation (5) (see footnote 12), we take a logarithmic approximation. We also approximate $\ln \Psi(\cdot)$ by $\beta_{5} s_{i j y}+\beta_{6} a_{i j}+\beta_{7} a_{i j} t_{y}$, where $s$ is a measure of expected future cost declines due to reallocation of fishing effort through trading, $a$ indicates the effect of expected future cost reductions on increases in fish stock abundance, and $t$ is an annual time index. ${ }^{8}$ Specifically, the relationship we bring to the quota asset price data is

$$
\begin{aligned}
\ln p_{i j q y}= & \beta_{1} \ln \pi_{i j q y}+\beta_{2} \ln \left(1+\tilde{r}_{q y}\right) \\
& +\beta_{3} \ln \theta_{i},+\beta_{4} \ln \left(1+g_{i}\right) \\
& +\beta_{5} s_{i j y}+\beta_{6} a_{i j}+\beta_{7} a_{i j} t_{y} \\
& +\beta_{8} d_{i}+\alpha_{q}+\alpha_{y}+V_{i j}+\varepsilon_{i j q y}
\end{aligned}
$$

where $p$ is the quarterly average quota asset price, $\pi$ is the contemporaneous quota lease price (as a measure of the annual profits from fishing), $\tilde{r}$ is the real interest rate, $\ln \theta$ is proxied by each species natural mortality rate (a measure of risk), and $g$ is proxied by a measure of expected future growth in the output price of fish species $i .^{9}$ We also include a dummy variable $(d)$ for shellfish stocks (i.e., abalone, rock lobster, and scallops), a set of quarterly fixed effects $\left(\alpha_{q}\right)$, a set of yearly fixed effects $\left(\alpha_{y}\right)$, a fish-stock-specific effect $\left(v_{i j}\right)$, whose specification varies depending on the estimation approach (e.g., fixed or random effects), and an independent and identically distributed error term $(\varepsilon)$. Species are denoted by the subscript $i$ and regions by $j$, so that each $i j$ combination indexes a different fishing quota market. Time is indexed by quarter $q$ of year $y$.

The model and accompanying discussion above imply the following hypotheses for the model: $\beta_{1}>0, \beta_{2}<0, \beta_{3}<0, \beta_{4}>0, \beta_{5}>0$, $\beta_{6}>0$, and $\beta_{7}<0$. Strict interpretation of the

\footnotetext{
${ }^{8}$ Ideally our specification would impose $\lim t \rightarrow \infty \ln \Psi(\cdot)=1$, but this would require a functional form necessitating nonlinear estimation in an instrumental variables panel data context. We have therefore opted for a linear approximation.

${ }^{9}$ Equation (3) is derived under the assumption that factors affecting profit growth (e.g., output prices or costs) persist indefinitely, and it is solved by assuming the convergence of an infinite sum. Therefore, factors that will either grow or decline only over the short-run, such as TAC changes, are not found in the long-run solution of asset prices.
} 
Table 2. Descriptive Statistics for Determinants of Fishing Quota Asset Prices

\begin{tabular}{lrrrr}
\hline Variable & Mean & Std. Dev. & \multicolumn{1}{c}{ Min. } & Max. \\
\hline Lease price (\$/ton) & 1,795 & 4,289 & 1 & 43,663 \\
Asset price (\$/ton) & 20,266 & 46,870 & 22 & 358,586 \\
Export price (\$/ton) & 8,319 & 12,096 & 630 & 61,009 \\
Export price growth rate & 0.013 & 0.023 & -0.027 & 0.071 \\
Interest rate & 0.064 & 0.022 & 0.027 & 0.110 \\
Normalized percentage of quota sold & 1.000 & 0.952 & 0.000 & 11.892 \\
Natural mortality rate & 0.222 & 0.174 & 0.045 & 1.000 \\
Reduced TAC (dummy indicating fishery had initial reductions) & 0.273 & 0.446 & 0 & 1 \\
Shellfish (dummy indicating shellfish quota market) & 0.116 & 0.320 & 0 & 1 \\
Number of leases per quarter & 17 & 20 & 1 & 194 \\
Number of asset sales per quarter & 4 & 4 & 1 & 75 \\
\hline
\end{tabular}

Note: Statistics are based on the 4,120 observation samples from the estimation of quota asset price determinants. Monetary figures are the year 2000 New Zealand dollars, which are typically worth about half a U.S. dollar. Tons are metric tons.

logarithmic approximation given by equation (6) further implies the following hypotheses about the specific magnitudes of certain coefficients: $\beta_{1}=1, \beta_{2} \approx-(1+r) /(r+\theta-g), \beta_{3} \approx$ $-\theta /(r+\theta-g)$, and $\beta_{4} \approx(1+g) /(r+\theta-g)$, where each of the variables in these formulae is taken to be its mean value (the point of approximation). We do not impose these as restrictions, but rather consider them when interpreting the findings below.

We estimate equation (6) using the comprehensive panel dataset described in detail in NSK, which was constructed using information from New Zealand government agencies and other sources. We include 152 fish stocks representing 32 different species that had entered the New Zealand ITQ system by 1998 . The data cover 14 years from the 1987-1988 fishing year until the end of the 2000-2001 fishing year. All monetary figures were adjusted for inflation to year 2000 New Zealand dollars, using the producer price index (PPI) from Statistics New Zealand. Table 2 gives descriptive statistics for the 4,120 observations that comprise the estimation sample; the included variables exhibit a large degree of variation.

As described above, the quota asset and lease prices are quarterly averages for each species-region specific fish stock quota market, based on more than 140,000 underlying lease transactions and more than 23,000 asset transactions. ${ }^{10}$ The real market interest rate, $\tilde{r}$, is

\footnotetext{
${ }^{10}$ About $30 \%$ of lease and $25 \%$ of sale observations that did not represent reliable market transactions were omitted. For more information on how these prices were identified, see NSK. In addition, 1,324 of the 4,120 observations have sale prices that are constructed from only one transaction and 281 observations have a lease price calculated from one trade. However, those observations with only one underlying sale transaction come from stocks
}

the 90-day New Zealand Treasury bill rate, adjusted for inflation using the New Zealand CPI. As a measure of variation in the risk premium across species, $\ln \theta$, we use each species' natural mortality rate. Species with higher mortality rates have population sizes that are typically more variable due to fewer age classes, which we argue leads to increasingly greater uncertainty in the amount of fish likely to be caught with a given level of effort. As a consequence, there is greater uncertainty in the profits from fishing high-mortality species, and we would therefore expect higher mortality rates to have a negative effect on quota asset prices. ${ }^{11}$ We base $g$ on the historic growth rate in output prices, where output prices are based on the export price per greenweight ton using data from Statistics New Zealand over the period 1986-2001, deflated using the NZ PPI (see NSK). ${ }^{12}$

Empirically, the components of the approximation to the $\Psi(\cdot)$ function are as follows. To represent expected future profit increases

that have, on average, 2.5 sales per quarter. For leases, this value is 9.4. This suggests that while some stocks may have isolated periods of low market activity, in general they feature a reasonable number of trades.

11 The New Zealand Ministry of Fisheries uses the mortality rate to construct a measure of natural variability that is factored into the setting of the TAC (Annala, Sullivan, and O'Brien 2000). The assumption is that a stock with higher natural mortality will have fewer age classes and therefore have greater fluctuations in biomass.

${ }^{12}$ We estimate the output price growth rate independently for each species based on a first-order autoregressive model of the log fish price, including a time trend, quarterly (seasonal) effects, and a constant term. The estimates for a small number of species are negative and to avoid taking the logarithm of a negative number, we add and subtract 1 in the denominator of equation (5). Another option would be to directly estimate the growth rate in lease prices, but this introduces econometric issues due to the endogeneity of lease prices. 
due to reallocation of fishing effort through trading, $s$, we use the annual percentage of quota assets sold for each fish stock, normalized by dividing by each stock's average percentage sold. The hypothesis is that reallocation of quota assets is an indication of expected future profits from that trade, most likely through cost reductions.

Improvements in profits through cost reductions can also occur as a result of improvements in fish stock abundance, and associated increases in the catch-per-unit-effort. We represent this feature using a dummy variable, $a$, that indicates whether each stock faced significant reductions upon implementation of the ITQ program. ${ }^{13}$ We expect that fisheries plagued by excess capacity and overfishing prior to the implementation of the ITQ system that also faced significant reductions in allowable catch at the outset of the ITQ program would experience greater increases in profitability through stock rebuilding and cost rationalization than fish stocks without a high degree of overfishing, everything else being equal. Thus, we would expect the coefficient on $a$ to be positive, indicating that for a given lease price, the asset price will be higher for stocks with fish stock rebuilding plans in place.

Over time, however, the gains from such improvements should be realized, implying that future gains will be lower. We capture this effect by interacting $a$ with a time trend, hypothesizing that over time the lease price will rise as stocks improve, and the effect on the asset price of additional future gains will diminish. Under these conditions, we would expect the coefficient on the interaction of $a$ and $t$ to be negative.

\section{Estimation Approach}

\section{Time-Series Properties of Data}

Before considering estimation of equation (6), it is essential to determine the time series properties of the asset and lease price series. If either one or both of the series are nonstationary, then standard regression techniques will be susceptible to the problem of spurious regression.

\footnotetext{
${ }^{13}$ We classified fish stocks as to whether they faced significant initial catch reductions under ITQs by using historical information on catch rates, TAC levels, and references in the literature (see supplementary material in NSK for more information). The following 33 fish stocks were so classified: CRA1-5, CRA7-8, BNS2, ELE3-5, JDO1, MOK1-3, ORH2B, SCH1-3, SCH5, SCH7-8 SKI3, SNA1-2, SNA8, SPO1-3, SPO7-8, TRE1, HPB2-3.
}

While testing for unit roots in panels is a relatively new enterprise, there are several tests available to researchers (see Banjeree [1999] for more information on the tests). We employ three tests, all of which can be thought of as panel data extensions or pooled versions of the Dickey-Fuller test (or Augmented Dickey-Fuller test when lags are included). Full details are given in the supplemental appendix (Newell, Papps, and Sanchirico 2007). In all three cases, we reject the hypothesis of a unit root in both the asset and lease price series at the $1 \%$ level. The same result holds when the tests are repeated using species-level (rather than stock-level) data. The agreement in the time series properties of the asset and lease prices satisfies, at least at the panel level, a necessary condition of the present-value model (Falk 1991). ${ }^{14}$

We also test for the possibility of nonstationarity in the quarterly New Zealand real interest rate for thirty-day Treasury bills and the quarterly species-level export price, which is used as an instrument in the econometric analysis for contemporary lease prices. In both cases, we reject the null hypothesis of a unit root. Therefore, the time series variables in the regressions to follow are all stationary, allowing us to draw inferences from the use of standard panel data techniques with variables in levels.

\section{Panel Estimation Techniques}

Because lease prices and asset prices are determined simultaneously in the ITQ market each period, it is likely that estimation of equation (6) suffers from simultaneity bias. Statistical tests for endogeneity of the lease price verify this concern. 15 We therefore use instrumental variables estimation throughout, instrumenting for the log lease price using the logged contemporaneous export price of fish and all other regressors, including stock fixed effects. The price of fish is an excellent instrument as it is a significant determinant of profits from fishing, it is highly correlated

\footnotetext{
${ }^{14}$ A testable implication of the present value model is that the time series properties of asset prices and dividends should be the same. That is, if rents are (non) stationary, then agricultural land prices should be (non) stationary. Falk (1991) finds that in the Iowa farmland market both series follow a unit root, while Clark, Fulton, and Scott (1993) reject the hypothesis that the two series have the same time series representations for Illinois farmland.

${ }^{15}$ Both the Wu-Hausman F-test and Durbin-Wu-Hausman chisquared test strongly reject ( $p$-value $<0.0001)$ the null hypothesis of exogeneity of the lease price (see Davidson and MacKinnon 1993).
} 
with quota lease prices $(\rho=0.77)$, and it is clearly exogenous. ${ }^{16}$ Our estimation approach follows Balestra and VaradharajanKrishnakumar (1987), employing a two-stage least squares generalization of the standard panel data estimators to correct for endogeneity. See Baltagi (2001) for an introduction to panel data models with endogenous explanatory variables.

Our first specification models the data for all stocks in a pooled fashion. This approach is appropriate if there are no unobserved stockspecific effects. In contrast, our second specification performs the within estimator, which is equivalent to a regression with a full set of stock-specific fixed effects. While the within estimator is consistent, it is not as efficient as other estimators (e.g., random effects) if the unobserved stock-specific effect is uncorrelated with the observed regressors. In addition, with the fixed effects approach it is not possible to recover coefficients on any of the time-invariant regressors, namely the export price growth rate, mortality rate, and recovering stock dummy.

Our third specification performs the between estimator, which is a regression of stockspecific averages over time. As such, this specification cannot identify coefficients on stock-invariant regressors, such as the interest rate. Finally, our fourth specification treats the stock-specific term, $v_{i j}$, as a random effect. This model is more efficient than within estimation when none of the regressors is correlated with the stock-specific effect, however, it is inconsistent when the opposite is true. This assumption of no correlation is typically assessed using a Hausman test. The random effects estimator has the advantage of controlling for stock-specific effects while at the same time allowing for estimation of time-invariant explanatory variables, which are of central interest to this article. Beyond the fixed or random effect, we assume that the remaining error is homoskedastic. This is supported by panel tests of both heteroskedasticity (Pagan and Hall 1983) and autocorrelation (Wooldridge 2002), neither of which rejected a homoskedastic error structure.

\footnotetext{
${ }^{16}$ It is reasonable to treat fish prices as given because New Zealand exports about $90 \%$ of its commercial catch, yet accounts for less than $1 \%$ of world fishing output. Even in the small number of cases in which New Zealand comprises a sizeable fraction of the world catch of individual species, these species have many near-perfect substitutes in the form of other "white fish."
}

\section{Estimation Results}

In table 3, we report the results of estimating equation (6) using the fishing quota asset and lease price data described above. Due to some observations having missing values for one or more of the variables, 4,120 observations were available for the four models that are reported. All the four specifications show a high degree of explanatory power, with $R^{2}$ values of 0.77 or above. Overall, the results are consistent with economic predictions about the parameters. The estimated coefficients generally have the expected signs and reasonable magnitudes and are stable across the different specifications.

Regarding the appropriateness of the different specifications, we find that a joint F-test of the fixed effects is highly significant, thereby opening up the standard errors and consistency of the pooled model to misspecification. On the other hand, a Hausman test comparing the fixed effects and random effects estimators clearly indicates that the random effects model is appropriate (i.e., the assumption of no correlation between the regressors and the random effect is not rejected). Hence, the random effects estimates are consistent and more efficient than the fixed effects (or between) estimates. Indeed, the stability of the coefficients across these specifications illustrates the consistency of the parameter estimates in the random effects model.

The four specifications reported in table 3 feature an estimated coefficient on log lease price of between 0.76 and 0.86 . We find that the random-effects estimate for the lease price coefficient lies between the within estimate (model ii) and the between estimate (model iii), as one would expect given that the random effects estimator is an efficient weighted average of the within and between estimators (when its assumptions are upheld). These results suggest that changes in lease prices are reflected very closely in changes in the contemporaneous quota asset prices. However, the point estimates are somewhat lower than the expected coefficient of 1 based on the simple present-value model given above, or based on the simple univariate relationship depicted in figure $2 .{ }^{17}$

\footnotetext{
${ }^{17}$ A $t$-test does not reject the null hypothesis that the coefficient on lease price is equal to 1 for specification (ii), but it does so for specifications (i), (iii), and (iv). We also found that the coefficient on lease price is somewhat higher when the sample is restricted to the second half of the sample period, compared to the first half. This is consistent with the market operating more efficiently the longer it has been in existence.
} 
Table 3. Determinants of Fishing Quota Asset Prices

\begin{tabular}{|c|c|c|c|c|}
\hline Variables & $\begin{array}{c}\text { (i) } \\
\text { Pooled }\end{array}$ & $\begin{array}{c}\text { (ii) } \\
\text { Within } \\
\text { (Fixed Effects) }\end{array}$ & $\begin{array}{c}\text { (iii) } \\
\text { Between }\end{array}$ & $\begin{array}{l}\text { (iv) } \\
\text { Random } \\
\text { Effects }\end{array}$ \\
\hline Logged lease price (instrumented) $(\ln \pi)$ & $\begin{array}{l}0.840^{* * *} \\
(0.016)\end{array}$ & $\begin{array}{l}0.861^{* * *} \\
(0.234)\end{array}$ & $\begin{array}{l}0.764^{* * *} \\
(0.046)\end{array}$ & $\begin{array}{l}0.834^{* * *} \\
(0.036)\end{array}$ \\
\hline Interest rate $(\ln (1+r))$ & $\begin{array}{c}-3.048 \\
(1.871)\end{array}$ & $\begin{array}{c}-3.966^{* *} \\
(1.961)\end{array}$ & & $\begin{array}{c}-3.708^{* * *} \\
(1.746)\end{array}$ \\
\hline Natural mortality rate $(\ln \theta)$ & $\begin{array}{c}-0.329^{* * *} \\
(0.071)\end{array}$ & & $\begin{array}{r}-0.382^{*} \\
(0.209)\end{array}$ & $\begin{array}{c}-0.331^{* *} \\
(0.167)\end{array}$ \\
\hline Growth in output prices $(\ln (1+g))$ & $\begin{array}{l}2.848^{* * *} \\
(0.583)\end{array}$ & & $\begin{array}{l}3.969^{* *} \\
(1.649)\end{array}$ & $\begin{array}{l}3.641^{* * *} \\
(1.334)\end{array}$ \\
\hline Normalized percentage of quota sold $(s)$ & $\begin{array}{c}0.013 \\
(0.012)\end{array}$ & $\begin{array}{c}0.013 \\
(0.013)\end{array}$ & & $\begin{array}{c}0.012 \\
(0.011)\end{array}$ \\
\hline $\begin{array}{l}\text { Fisheries with initial reductions in } \\
\text { TAC }(a) \text { (dummy variable) }\end{array}$ & $\begin{array}{c}0.099^{*} \\
(0.054)\end{array}$ & & $\begin{array}{c}0.192^{* *} \\
(0.077)\end{array}$ & $\begin{array}{c}0.124^{*} \\
(0.074)\end{array}$ \\
\hline $\begin{array}{l}\text { Interaction of time with variable } \\
\text { indicating fisheries with initial } \\
\text { reductions in TAC }(a \bullet t)\end{array}$ & $\begin{array}{c}0.006 \\
(0.006)\end{array}$ & $\begin{array}{c}0.006 \\
(0.008)\end{array}$ & & $\begin{array}{c}0.007 \\
(0.006)\end{array}$ \\
\hline Shellfish (dummy variable) & $\begin{array}{l}0.271^{* * *} \\
(0.056)\end{array}$ & & $\begin{array}{l}0.592^{* * *} \\
(0.155)\end{array}$ & $\begin{array}{l}0.317^{* * *} \\
(0.124)\end{array}$ \\
\hline Seasonal effects & $\begin{array}{l}\text { Jointly } \\
\text { significant }\end{array}$ & $\begin{array}{c}\text { Jointly } \\
\text { significant }\end{array}$ & - & $\begin{array}{c}\text { Jointly } \\
\text { significant }\end{array}$ \\
\hline Fish stock effects & - & $\begin{array}{c}\text { Jointly } \\
\text { significant }\end{array}$ & - & - \\
\hline Year effects & $\begin{array}{c}\text { Jointly } \\
\text { significant }\end{array}$ & $\begin{array}{l}\text { Jointly } \\
\text { significant }\end{array}$ & - & $\begin{array}{c}\text { Jointly } \\
\text { significant }\end{array}$ \\
\hline Constant term & $\begin{array}{l}3.588^{* * *} \\
(0.205)\end{array}$ & $\begin{array}{l}3.567^{* * *} \\
(1.320)\end{array}$ & $\begin{array}{l}3.853^{* * *} \\
(0.284)\end{array}$ & $\begin{array}{l}3.644^{* * *} \\
(0.266)\end{array}$ \\
\hline Number of quarterly observations & 4,120 & 4,120 & 4,120 & 4,120 \\
\hline Number of panels (quota markets) & 152 & 152 & 152 & 152 \\
\hline$R^{2}$ & 0.78 & 0.77 & 0.78 & 0.79 \\
\hline
\end{tabular}

Note: The dependent variable is the logged average quarterly asset price. Standard errors are shown in parentheses. Triple asterisk $(* * *)$ indicate significance at the $1 \%$ level, double $\left({ }^{* *}\right)$ at the $5 \%$ level, and single $\left({ }^{*}\right)$ at the $10 \%$ level. The data are a panel of observations for species- and region-differentiated quota markets over 14 years. The logged lease price is instrumented using the logged export price and all other regressors. The estimation method is indicated above each column.

It is not clear how much this lower-thanexpected estimated coefficient casts doubt on the simple present value model represented by equation (6), although it suggests that it may not hold exactly. One possibility is an errorsin-variables problem, with the standard implication that the resulting coefficient is biased toward zero. Another possibility is that the various controls included in the model (e.g., year effects) are simply reducing the amount of variation in lease prices available for estimating that coefficient. This conjecture is supported by a simple random or fixed effects regression of log quota asset prices on (instrumented) log quota lease prices, with no other controls. In these simple models the coefficient on the log lease price is 0.98 in the case of the random effects model and 1.04 in the fixed effects model, with neither of these estimates being statistically different from 1 .
A further possibility is that quota prices adjust slowly in response to changes in profit conditions, and that the contemporaneous lease price is an insufficient indicator of expectations about future profits. This possibility could warrant the inclusion of multiple lagged values of the lease price in the estimation equation, as in the model of Burt (1986). We explored this by including the one-year and two-year lagged lease price in the fixed and random effects models, finding that these lagged prices were statistically insignificant and did not increase the total effect of lease prices on asset prices. In addition, we explored an adaptive expectations model (as described earlier) by including the lagged asset price as a regressor and estimating the model according to the approach of Arellano and Bond (1991) to account for the lagged dependent variable. The estimated coefficient on the lagged asset price was very small (0.08) and was statistically insignificant 
from zero, again suggesting that using the contemporaneous lease price in conjunction with the other variables affecting expectations is acceptable.

In general, the estimated coefficients on the other regressors are consistent with the predictions of the theory outlined earlier. Periods with higher interest rates have lower asset prices, ceteris paribus, as predicted by the basic present value model. As measured by higher mortality rates, stocks with more uncertain returns also tend to have lower asset prices, as is expected in the presence of risk-aversion.

With respect to the magnitude of these estimates, we refer back to the implications of the strict interpretation of the logarithmic approximation given by equation (6), which are $\beta_{2} \approx-(1+r) /(r+\theta-g)$ and $\beta_{3} \approx$ $-\theta /(r+\theta-g)$, where each of the variables in these formulae is taken to be its mean value. For $r=6.4 \%$ and $r+\theta-g=8.9 \%$ (based on the mean lease-to-asset price ratio), we would expect $\beta_{2} \approx-12$. Our estimate is $\hat{\beta}_{2}=-4$, which is in the same realm, but somewhat muted relative to what the simple theory suggests. At the same time, an average risk premium of $\theta=3.8 \%$ (based on $\theta=8.9 \%-r+$ $g$ and $g=1.3 \%$ ) yields $\beta_{3} \approx-0.4$, which is similar to our estimate of $\hat{\beta}_{3}=-0.3$. Note that although we do not have a direct measure of the risk premium, the mortality rate proxy we use should yield approximately the same estimated coefficient if it is directly proportional to the true measure of $\ln \theta$.

Table 3 also reports evidence that stocks with faster-growing returns have higher asset prices, controlling for other factors. As noted earlier, growth in returns may be due to rising prices or falling costs. The former clearly has an important impact on quota asset prices, as growth in export prices is found to be strongly associated with asset prices in all specifications where this effect could be estimated. Regarding the magnitude of this effect, earlier we set out the hypothesis that $\beta_{4} \approx(1+g) /(r+\theta-g)$, which yields $\beta_{4} \approx 12$, while our estimate is approximately $\hat{\beta}_{4}=4$. Interestingly, although the estimated coefficients on $\ln (1+r)$ and $\ln (1+g)$ are both lower than the theoretical expectation, they are approximately equal and opposite in sign, as suggested by the theory. One possible explanation is the presence of measurement error (the "errorsin-variables" problem), resulting in the usual bias toward zero.

Stocks where fishing costs are expected to fall over time are also found to have higher asset prices. This is seen in table 3 in two ways. First, recovering stocks tend to have higher asset prices, as expected. Contrary to our hypothesis, however, we find no evidence that this premium has dissipated over time, with a very small and statistically insignificant coefficient on the time trend found for recovering stocks. ${ }^{18}$ One explanation for this finding may simply be that the expected future recovery of these stocks has yet to be fully realized, due to the life-cycle characteristics of the fish populations and/or ocean environmental conditions.

Second, we find that high levels of trade in the quota asset market are associated with higher asset prices across stocks, after controlling for other effects, but that this effect is statistically insignificant. The positive point estimate is consistent with the notion that stocks experiencing a high degree of rationalization after the introduction of the quota system feature decreasing fishing cost and thus become increasingly valuable over time.

Finally, the shellfish dummy (i.e., for rock lobster, abalone, and scallops) is found to enter specifications (i), (iii), and (iv) with a highly significant positive coefficient. This suggests that shellfish stocks tend to have higher asset prices than other stocks, ceteris paribus. One possible explanation for this additional effect of shellfish stocks is that the biomass of these species is typically estimated with more precision, and, hence, their catch rates are more certain. There is also anecdotal evidence that these stocks tend to have more effective cooperative management institutions (Yandle 2003).

\section{Conclusion}

When there are competitive fishing quota markets, rational asset pricing theory suggests that the price of quota should reflect the expected present value of future profits in the fishery. Evidence of economically rational asset prices implies that the market is conveying appropriate incentives to quota owners. Unless the TACs are set to achieve the optimal stock levels, however, quota prices are unlikely to internalize the full stock externality. Nevertheless,

\footnotetext{
${ }^{18}$ Because some fish stocks experienced nonmarginal cuts in TAC after the introduction of the ITQ system, we tested whether the year-to-year percentage change in TAC, or the TAC relative to its initial value, had any influence on the results. For both specifications, we also interacted the TAC change variable with a dummy variable indicating whether the change was positive or negative (i.e., we allowed for differential effects of TAC cuts or TAC increases). None of these variables were found to have a statistically significant effect on the quota price when added to the model.
} 
the incentives will be more closely aligned with economic optimality than they would be under traditional fishery management methods.

Random effects and other panel data models revealed that quota asset prices were related to contemporaneous lease prices in the expected manner in the New Zealand ITQ market. We also find that asset prices are higher when interest rates are low and for stocks that experience less biological fluctuation. Furthermore, stocks with higher growth rates of fish output prices tend to have higher quota asset prices. We also find that stocks thought to have experienced reductions in costs since the introduction of the ITQ market have higher asset prices, ceteris paribus, although these effects did not diminish over time as expected.

We conclude, therefore, that the New Zealand quota system as a whole has functioned reasonably well and the prices at which quota have sold appear to reflect expectations about future returns on specific fish stocks. The U.S. government's ocean action plan and recent legislative proposals encourage the regional fishery management councils to adopt market-based systems for fisheries management. For skeptics of these plans, and for fishery managers currently designing ITQ programs in the Gulf of Alaska, Gulf of Mexico, and along the west coast of the United States, our results provide additional statistical evidence that real world ITQ programs are transmitting the correct incentives to quota owners to address the common pool problem in ocean fisheries.

More generally, the relationships between the assets and dividends are further empirical support for the ability of tradable rights systems to lead to a more efficient utilization of resources.

\section{[Received June 2005; accepted May 2006.]}

\section{References}

Alston, J.M. 1986. "An Analysis of Growth of U.S. Farmland Prices, 1963-82." American Journal of Agricultural Economics 68:1-9.

Annala, J.H. 1996. "New Zealand's ITQ System: Have the First Eight Years Been a Success or a Failure?" Reviews in Fish Biology and Fisheries 6:43-62.

Annala, J.H., K.J. Sullivan, and C.J. O'Brien. 2000. Report from the Fishery Assessment Plenary: Stock Assessments and Yield Estimates. Wellington: New Zealand Ministry of Fisheries.
Arnason, R. 1990. "Minimum Information Management in Fisheries." Canadian Journal of Economics 23:630-53.

Arellano, M., and S. Bond. 1991. "Some Tests of Specification for Panel Data: Monte Carlo Evidence and an Application to Employment Equations." Review of Economic Studies 58:277-97.

Balestra, P., and J. Varadharajan-Krishnakumar. 1987. "Full Information Estimations of a System of Simultaneous Equations with Error Component Structure." Econometric Theory 3:223-46.

Baltagi, B.H. 2001. Econometric Analysis of Panel Data, 2nd ed. New York: John Wiley and Sons.

Banerjee, A. 1999. "Panel Data Unit Roots and Cointegration: An Overview." Oxford Bulletin of Economics and Statistics Special Issue:60729.

Barichello, R. 1996. "Capitalizing Government Program Benefits: Evidence of the Risk Associated with Holding Farm Quotas." In J.M. Antle and D.A. Sumner, eds. The Economics of Agriculture: Papers in Honor of D. Gale Johnson, Volume 2. Chicago: University of Chicago Press, pp. 283-99.

Barry, P.J. 1980. "Capital Asset Pricing and Farm Real Estate." American Journal of Agricultural Economics 62:549-53.

Batstone, C.J., and B.M.H. Sharp. 2003. "Minimum Information Management Systems and ITQ Fishery Management." Journal of Environmental Economics and Management 45:492504.

. 1999. "New Zealand's Quota Management System: The First Ten Years." Marine Policy 23:177-90.

Burt, O.R. 1986. "Econometric Modeling of the Capitalization Formula for Farmland Prices." American Journal of Agricultural Economics 68:10-26.

Campbell, J.Y. 2000. "Asset Pricing at the Millennium." Journal of Finance 55:1515-67.

Campbell, J.Y., A.W. Lo, and A.C. MacKinley. 1997. The Econometrics of Financial Markets. Princeton, NJ: Princeton University Press.

Casey, K.E., J. Wilen, and C. Dewees. 1995. "The Effects of Individual Vessel Quota in the British Columbia Halibut Fishery." Marine Resource Economics 10:211-30.

Clark, J.S., M.E. Fulton, and J.T. Scott. 1993. "The Inconsistency of Land Values, Land Rents and Capitalization Formulas." American Journal of Agricultural Economics 75:147-55.

Cochrane, J.H. 2001. Asset Pricing. Princeton, NJ: Princeton University Press. 
— 1992. "Explaining the Variance of PriceDividend Ratios." The Review of Financial Studies 2:243-80.

Davidson, R., and J. MacKinnon. 1993. Estimation and Inference in Econometrics. New York: Oxford University Press.

Dewees, C.M. 1998. "Effects of Individual Quota Systems on New Zealand and British Columbia Fisheries." Ecological Applications 8:S133S138.

Falk, B. 1991. "Formally Testing the Present Value Model of Farmland Prices." American Journal of Agricultural Economics 73:1-10.

Fama, E.F. 1991. "Efficient Capital Markets: II." Journal of Finance 46:1575-617.

—. 1998. "Market Efficiency, Long-Term Returns, and Behavioral Finance." Journal of Financial Economics 49:283-306.

Huppert, D.D., G.M. Ellis, and B. Noble. 1996. "Do Permit Prices Reflect the Discounted Value of Fishing? Evidence from Alaska's Commercial Salmon Fisheries." Canadian Journal of Fisheries and Aquatic Sciences 53:761-67.

Just, R.E., and J.A. Miranowski. 1993. "Understanding Farmland Price Changes." American Journal of Agricultural Economics 75:156-68.

Karpoff, J.M. 1984a. "Insights from the Markets for Limited Entry Permits in Alaska." Canadian Journal of Fisheries and Aquatic Sciences 41:1160-66.

1984b. "Low-Interest Loans and the Markets for Limited Entry Permits in the Alaska Salmon Fisheries." Land Economics 60:69-80. 1985. "Non-Pecuniary Benefits in Commercial Fishing: Empirical Findings from the Alaska Salmon Fisheries." Economic Inquiry 23:15974.

LeRoy, S.F. 1989. "Efficient Capital Markets and Martingales." Journal of Economic Literature 27:1583-621.

McGough, B., A. Plantinga, and B. Provencher. 2004. "The Dynamic Behavior of Efficient Timber Prices." Land Economics 80:95-108.

Melichar, E. 1979. "Capital Gains versus Current Income in the Farming Sector." American Journal of Agricultural Economics 61:1085-92.
Newell, R.G., K. Papps, and J.N. Sanchirico. 2007. "AJAE Appendix: Asset Pricing in Created Markets." Unpublished manuscript. Available at: http//agecon.lib.umn.edu.

Newell, R.G., J.N. Sanchirico, and S. Kerr. 2005. "Fishing Quota Markets." Journal of Environmental Economics and Management 49:43762.

Orazem, P., and J. Miranowski. 1986. "An Indirect Test for the Specification of Expectation Regimes." Review of Economics and Statistics 68:603-09.

Pagan, A.R., and D. Hall. 1983. "Diagnostic Tests as Residual Analysis.” Econometric Reviews 2:159-218.

Robison, L.J., D.A. Lins, and R. VenKataraman. 1985. "Cash Rents and Land Values in U.S. Agriculture." American Journal of Agricultural Economics 67:794-805.

Sanchirico, J.N., D. Holland, K. Quigley, and M. Fina. 2006. "Catch-Quota Balancing in Multispecies Individual Fishing Quotas." Marine Policy 30(6): 767-85.

Shalit, H., and A. Schmitz. 1982. "Farmland Accumulation and Prices." American Journal of Agricultural Economics 64:710-19.

Wilson, N., and D.A. Sumner. 2004. "Explaining Variations in the Price of Dairy Quota: Flow Returns, Liquidity, Quota Characteristics, and Policy Risk." Journal of Agricultural and Resource Economics 29:1-16.

Wooldridge, J.M. 2002. Econometric Analysis of Cross Section and Panel Data. Cambridge, MA: MIT Press.

Yandle, T. 2001. "Market-Based Natural Resource Management: An Institutional Analysis of Individual Tradable Quota in New Zealand's Commercial Fisheries." $\mathrm{PhD}$ dissertation, Department of Political Science, Indiana University.

2003. "The Challenge and Strength of Rock Lobster Fisheries Governance in New Zealand: Combining Grassroots Values with Centralized Leadership." Paper presented at Fisheries Coops \& Beyond, University of Alaska, Anchorage AK, 23-24 June. 